\title{
A IGREJA COMO EDUCADORA: O ASILO DE SANTO ANTÔNIO FORMANDO A MULHER CRISTÃ DE TRABALHO E PIEDADE $(1878-1888)^{1}$
}

\author{
Benedito Gonçalves Costa ${ }^{2}$ \\ Maria do Perpétuo Socorro Gomes de Souza Avelino de França ${ }^{3}$ \\ Universidade do Estado do Pará - UEPA
}

\section{RESUMO}

Este artigo tem como objetivo analisar o papel da Igreja Católica no campo da educação religiosa e escolar na Amazônia paraense, na segunda metade do século XIX, tendo como foco de análise, o Asilo de Santo Antônio, criado pelo bispo D. Antônio de Macedo Costa, para educar meninas desvalidas e pensionistas na capital da Província do Pará em 1871. Trata-se de um trabalho do tipo documental e bibliográfico. As fontes históricas utilizadas foram os Relatórios dos Presidentes da Província do Pará, os jornais O Liberal do Pará (1869 a 1889), A Estrela do Norte (1863 - 1869) e A Boa Nova (1871 - 1883) e Constituições e Regras do Instituto Religioso das Irmãs Mestras de Santa Dorotéia (1851), entre outras. Os autores que dão suporte às análises são Azzi (1982), Rossetto (1984), Bezerra Neto (1998), Maués (1999), Lustosa (1992), Manoel (2008), Neves (2009), Martins (2002), e outros. As meninas desvalidas e pensionistas eram educadas nos princípios da religião católica romanizadora com duas categorias de saberes: religioso e profano. Para D. Antônio de Macedo Costa, a Igreja seria a grande educadora do povo e o Asilo de Santo Antônio, a instituição que iria formar a mulher cristã de trabalho e piedade, aquela que iria ajudar a regenerar a sociedade.

Palavras-chave: Asilo; Educação de Meninas; Romanização; Amazônia Paraense.

\section{THE CHURCH AS EDUCATOR: SANTO ANTÔNIO ASYLUM FORMING THE CHRISTIAN WOMAN OF WORK AND PIETY}

\begin{abstract}
This article aimed understanding the role of the Catholic Church in the field of religious a and scholar education in Pará Amazon in the second half of the nineteenth century, having as analytical focus, Santo Antônio Asylum created by Bishop Antonio de Macedo Costa to educate girls underprivileged and pensioners in the capital of Pará Province in 1871. This is a bibliographic and documentary study. The historical sources used were the reports of Presidents of Pará Province, newspapers O Liberal do Pará (1869-1889), A Estrela do Norte (1863 to 1869) and A boa Nova (1871-1883) and Constitutions and Rules from Religious Institute of the Sisters Teachers of Santa Dorotéia (1851) among others. The authors that support the analyses are Azzi (1982), Rossetto (1984), Bezerra Neto (1998), Maués (1999), Lustosa (1992), Manoel (2008), Neves (2009), Martins (2002) and others. The underprivileged and pensioners girls were educated according with the principles of Romanised Catholic religion, with two knowledge categories: religious and profane. To bishop Antônio de Macedo Costa, the Church would be the big educator to the people and the Santo Antônio Asylum, the instituition that would form Christian woman of work and piety, the responsible to help in the society regeneration.
\end{abstract}

Keywords: Asylum; Girls' Education; Romanization; Pará Amazon. 


\section{Introdução}

O presente artigo tem por objetivo analisar o papel da Igreja Católica no campo da educação religiosa e escolar na Amazônia paraense, na segunda metade do século XIX, tendo como foco de análise o Asilo de Santo Antônio, criado pelo bispo D. Antônio de Macedo Costa, para educar meninas desvalidas e pensionistas na capital da Província do Pará.

Trata-se de uma pesquisa documental e bibliográfica. Pesquisas cujos objetivos são estudar a escola e seu fazer pedagógico devem centrar suas análises na cultura dessa instituição, pois, de acordo com Dominique Julia (2001), o estudo da cultura escolar nos permite fazer uma "análise precisa das relações conflituosas ou pacíficas que ela mantém" com as demais culturas que lhes são contemporâneas: cultura religiosa, política e popular. Portanto, de acordo com esse autor, a cultura escolar deve ser entendida "como um conjunto de normas que definem conhecimentos a ensinar e condutas a inculcar", assim como também, "um conjunto de práticas que permitem a transmissão de conhecimentos e a incorporação de comportamentos" (JULIA, 2001, p.10-11).

A pesquisa documental, de acordo com Rodrigues e França (2010, p. 55), "utiliza materiais que não receberam ainda um tratamento analítico, ou que podem passar por novas análises de acordo com os objetivos da pesquisa". Segundo as autoras, apesar de existir uma proximidade entre a pesquisa documental e a pesquisa bibliográfica, "a diferença essencial entre elas está na natureza das fontes. A primeira trabalha com fontes primárias, e a segunda se vale "fundamentalmente das contribuições dos diversos autores sobre determinado assunto".

Partindo desse pressuposto, lançamos mão neste estudo dos autores Riolando Azzi (1982), Rossetto (1984), Bezerra Neto (1998), Maués (1999), Lustosa (1992), Manoel (2008), Neves (2009), Martins (2002), e outros, para compreendermos a trama da cultura escolar no seio do Asilo de Santo Antônio no final do século XIX na Amazônia paraense. E como fontes documentais os Relatórios dos Presidentes da Província do Pará, os jornais O Liberal do Pará (1869 a 1889), A Estrela do Norte (1863 - 1869) e A Boa Nova (1871 $1883)^{4}$, Constituições e Regras do Instituto Religioso das Irmãs Mestras de Santa Dorotéia $(1851)^{5}$ entre outros.

A sequência organizacional deste artigo está dividada em três partes. Na primeira, trazemos a concepção de Igreja romanizadora e sua luta pela hegemonia do campo educacional na segunda metade do século XIX. Na segunda, destacamos a presença do bispo do Pará, D. Antônio de Macedo Costa, na defesa de uma política educacional sob os domínios da Igreja para desenvolver a Amazônia. Na última, trazemos alguns aspectos da educação das meninas no Asilo de Santo Antônio sob as orientações da Igreja reformadora, cujos objetivos eram forma a mulher cristã de trabalho e piedade, a fim de promover a regeneração social pela atuação da mulher cristã dentro do lar doméstico.

\section{A Igreja romanizadora na luta pela hegemonia do campo educacional na segunda metade do século XIX.}

Um certo ramo da historiografia tem apontado que a passagem da Idade Média para a Idade Moderna significou uma série de transformações nos campos político, econômico e cultural, que colocou esses dois períodos históricos em oposição, principalmente pelo surgimento de dois grupos antagônicos: a nobreza e a burguesia. No entanto, para o historiador Perry Anderson (1995) o fim da Idade Média não significou o desaparecimento 
das relações feudais, pois os Estados Nacionais Absolutistas foram uma produção da nobreza feudal para tentar se manter no poder. Portanto, segundo Perry Anderson, no absolutismo não ocorreu um equilíbrio entre as duas forças antagônicas, nobreza e burguesia, mas prevaleceu o aparelho de dominação feudal sujeitando os camponeses à sua posição tradicional, favorecendo com isso também os interesses da burguesia (ANDERSON, 1995).

Nesse sentido, a Igreja (alto clero), enquanto membro da nobreza, não sofreu abalos profundos que provocassem sua derrocada. E mesmo no período de maior crise que provocou a divisão da Europa entre católicos e prostestantes, o esfacelamento da Igreja não aconteceu, pelo contrário, essa crise na Igreja favoreceu positivamente o Cristianismo de acordo com o historiador Jean Delumeau (1983). Para esse autor, o movimento de Reforma Protestante e Contra-Reforma significou o surgimento de um cristianismo renovado e isso foi, segundo Delumeau, um dos aspectos positivos do Renascimento (DELUMEAU, 1983).

No campo católico, essa renovação, ou reforma, configurou-se no movimento chamado de Romanização. Esse termo significa o processo pelo qual a Igreja Católica buscou desenvolver uma reforma interna a fim de combater os perigos da modernidade que ameaçavam sua autonomia no mundo. Esses reformadores ficaram conhecidos como romanizadores ou ultramontanos. De acordo com David Gueiros Vieira (1980), o termo ultramontano era usado desde o século XI para os cristãos que habitavam para além dos montes da Itália, como os franceses que buscavam liderança espiritual e institucional na Santa Sé, em Roma. Já na segunda metade do século XIX, quando o liberalismo e outras religiões começaram a ameaçar a autonomia da Igreja no mundo, o movimento de romanização também cresceu e chegou ao Brasil "levando o clero local a integrar-se na disputa pela sobrevivência do catolicismo nessas terras" (MARTINS, 2002, p. 73).

De acordo com Raymundo Heraldo Maués (1999, p. 121), os romanizadores no Brasil buscavam "entre outras coisas, uma maior aproximação da Igreja do Brasil de Roma, e consequentemente, uma espécie de europeização do catolicismo brasileiro". Para Fernando Arthur de Freitas Neves (2009), a romanização significava, entre outras coisas, o respeito à autoridade Papal e aos bispos no campo espiritual e temporal, a autonomia da Igreja frente ao poder estatal, a unificação da liturgia a partir das orientações de Roma, a moralização do clero, a reestruturação dos Seminários e unificação do ensino do catecismo, ou seja, a substituição do catolicismo tradicional (popular), construído no Brasil a partir do regime de padroado, por um catolicismo de modelo diocesano segundo as diretrizes de Roma (NEVES, 2009, p. 25).

Nesse sentido, os bispos brasileiros, na tentativa de combater aquilo que eles consideravam uma ameaça, iniciaram um movimento de reforma que buscava "substituir o antigo regime de Igreja-Cristandade, de origem medieval, vigente durante o período colonial, pelo modelo de Igreja Hierárquica, implantada na Europa a partir da Reforma Tridentina" (AZZI, 1982, p. 10). De acordo com esse autor, pelo primeiro modelo, a Igreja era concebida como unida ao Estado, tendo o Imperador um duplo poder: de chefe do poder político e religioso. Por esse modelo (Igreja-Cristandade), a igreja era considerada um departamento de Estado e o clero fazia parte do funcionalismo público. De acordo com o novo modelo que os bispos tentaram implantar, o Estado e a Igreja teriam papeis distintos. A primeira "era apresenta como uma sociedade perfeita que se ocupava dos problemas espirituais" e o segundo deveria se ocupar apenas "das questões atinentes à ordem material (AZZI, 1982, p. 10).

Na Amazônia, de acordo com João Santos (1992), as décadas de 1840 a 1880 corresponderam aos tempos mais importantes da romanização na região, pois nesse 
período os bispos D. José Afonso de Moraes Torres e D. Antônio de Macedo Costa se destacaram entre o episcopado brasileiro como reformadores da Igreja no país. O governo do primeiro bispo reformador encontrou uma Diocese devastada pela guerra civil conhecida como Cabanagem (1835-1840) e tentou reerguer os trabalhos eclesiásticos, inclusive na busca da ampliação da catequese de populações indígenas. Entretanto, as inúmeras dificuldades enfrentadas nos 15 anos de governo, o fizeram renunciar ao episcopado da Diocese do Pará. Segundo João Santos (1992, p.306), os motivos que levaram D. José Afonso a renunciar foram: "a escassez do clero, dificuldades na reforma do clero antigo, falta de saúde e escrúpulos de consciência com relação ao cumprimento exato do seu múnus pastoral".

O novo bispo do Pará, D. Antônio de Macedo Costa, recebeu a sagração no Palácio Episcopal, sede da nova Diocese e passou a ocupar o prédio do Colégio de Santo Alexandre, no centro da cidade (LUSTOSA, p. 25). Esse Colégio e a Igreja de Santo Alexandre foram construídos pelos padres jesuítas no século XVII e, no século seguinte, o colégio passou também a abrigar o Seminário Diocesano (LUSTOSA, 1992, p.114). De acordo com Karla Denise Martins (2002), esta atitude de D. Macedo Costa, de tomar para si a organização do Palácio Episcopal, localizado no Colégio de Santo Alexandre, tinha como objetivo "atribuir à sua missão um caráter simbólico mais amplo: o de 'restaurar' a obra empreendida pelos Jesuítas em tempos passados, evocando sempre a imagem do Padre Vieira". Segundo a autora, isso daria a Romanização empreendida por D. Antônio de Macedo Costa um "duplo sentido: renovar o catolicismo na Amazônia e, ao mesmo tempo, retomar o trabalho missionário interrompido por um gesto do poder secular" (MARTINS, 2002, p. 88).

Uma das primeiras medidas de D. Antônio de Macedo Costa foi no campo da educação, começando com a reforma do Seminário Diocesano. Para ele, a reforma dos seminários brasileiros iria ajudar na formação de um clero ilustrado, apto a desenvolver a regeneração moral do país pela prática da religião católica. Nesse sentido, D. Macedo Costa concebeu a educação religiosa e a instrução secular como inseparáveis, mas com a supremacia da primeira. Para ele, só um clero ilustrado seria capaz de manter as "sólidas bases o edifício da moralidade pública", por isso, a educação religiosa estava à "frente de todas as obras da inteligência e indústria humana, na frase de um moderno economista, semelhante à Arca da Aliança, que marchava diante do povo". Portanto, para o sustento da religião era fundamental "um clero instruído, dedicado, cheio do espírito de sua sublime vocação". Segundo D. Macedo Costa, um clero instruído não seria apenas importante para a religião e renascimento dos costumes cristãos e clericais, mas também para ajudar na "restauração dos costumes públicos e sociais, princípio de todo o verdadeiro progresso e civilização" (A ESTRELA DO NORTE, 22-03-1863, p. 90).

Para o clero romanizador, cabia à Igreja a administração dos seminários e instituições educativas eclesiásticas, como previa o Decreto do Concílio de Trento (1545 a 1563), Nesse documento, de acordo com D. Macedo Costa, determinava-se que os Seminários deveriam ser confiados aos bispos, os quais deveriam escolher e aprovar professores idôneos e prescrever-lhes o que deveriam ensinar. Além disso, outro documento da Igreja construído no Concílio de Aquiléia de 1856 reafirmou a autonomia dos bispos quanto à administração dos Seminários e determinou, segundo D. Macedo Costa, que cabia à igreja a supremacia da educação da juventude. Por esse motivo, D. Antônio de Macedo Costa defendia que a Igreja tinha a missão de "difundir por toda a parte a instrução, criando escolas gratuitas em benefício da mocidade e inspirando aos maiores gênios o heróico pensamento de se dedicarem ao penoso ensino da classe pobre e miserável" (COSTA, In: LUSTOSA, 1992, p. 58). 
Para D. Antônio de Macedo Costa, a Igreja deveria criar uma rede de escolas católicas para "difundir por toda a parte a instrução, criando escolas gratuitas em benefício da mocidade e também inspirar "os maiores gênios", ou seja, os intelectuais e autoridades políticas ao "heróico pensamento de se dedicarem ao penoso ensino da classe pobre e miserável”, isto é, incutir na cabeça desses gênios que deveriam promover a instrução dos pobres e miseráveis mesmo sendo isso um "penoso" trabalho. Portanto, a Igreja seria no mundo, na visão de D. Antônio de Macedo Costa, a educadora por excelência, aquela que tinha a missão de salvar e regenerar o povo pela educação moral e religiosa, e o Estado deveria, junto com a Igreja, se dedicar ao ensino da "classe pobre e miserável" para se alcançar o progresso e a civilização (COSTA, In: LUSTOSA, 1992, p. 58).

Foi com essa convicção que D. Antônio de Macedo Costa, ao assumir os trabalhos eclesiásticos na Diocese do Pará, tratou logo de reformar o Seminário de Belém, mandar jovens para estudar na Corte, Bahia e Europa e criar instituições educativas para educar meninas órfãs e desvalidas (Asilo de N. S. do Carmo em 1871, que depois passou a chamar-se Asilo de Santo Antônio em 1873) e para meninos pobres se instruírem e aprenderem uma profissão (Instituto de Artes e Ofícios e Agrícola da Providência em 1882), a fim de promover o progresso e a civilização da Amazônia.

\section{D. Antônio de Macedo Costa e a proposta educacional romanizadora para desenvolver a Amazônia}

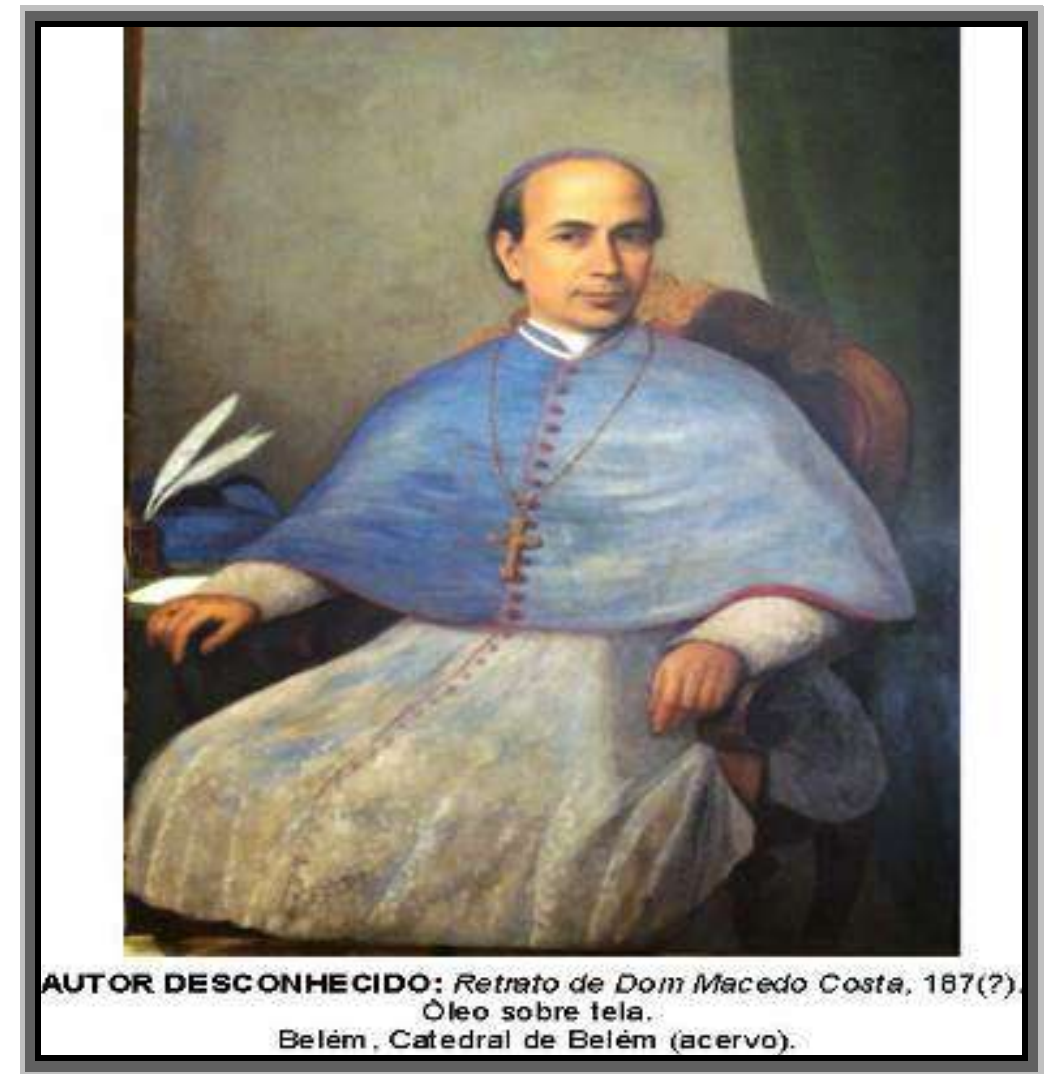

Figura 01: Imagem de D. Antônio de Macedo Costa.

Fonte: http://www.dezenovevinte.net/obras/pcbelem_rfcm.htm 
Elevar, pois o nível intelectual e moral dos povos do Amazonas é uma questão econômica de primeira ordem. Que digo eu senhores? Remontemos a mais subida esfera? É uma questão política, uma questão social, uma questão de humanidade, um grave problema do ponto de vista da civilização e do cristianismo. (COSTA, 1883, p.4)

Para D. Antônio de Macedo Costa, só existia um caminho seguro que faria a Amazônia trilar os caminhos da civilização: elevar o nível intelectual e moral do seu povo. Para ele, investir na instrução e educação moral seria investir no desenvolvimento da própria economia. E isso era uma questão política, social e de humanidade, pois o baixo nível intelectual e moral do povo seria um grave problema que impediria não só o avanço da civilização, mas também do cristianismo. Para o enfrentamento desse problema, D. Antônio apresentou um projeto de desenvolvimento para a Amazônia, cujos princípios estavam centrados na educação cristã, e que significava dar ao povo a instrução escolar e a educação moral pelo ensino da religião católica, a fim de se alcançar uma sociedade moralista, pacífica e próspera, “A educação da mocidade vazada nos moldes cristãos dará uma sociedade moralista, pacífica e prospera, como a que voltar ao tipo pagão, ao materialismo, produzirá infalivelmente, a anarquia, a ruína, a morte" (A BOA NOVA, 23-07-1879, p.1).

Para evitar a disseminação da "anarquia" e "ruína" por uma educação do tipo pagã e materialista, D. Antônio de Macedo Costa e seus auxiliares romanizadores propuseram uma educação centrada nos princípios cristãos, que pregava acima de tudo o temor a Deus, o respeito à religião, o amor ao trabalho, a abnegação do próprio interesse, a caridade para com o próximo, a afabilidade para com todos, o horror à falsidade e amor à verdade, o afeto para com os pais de família, a comiseração para com os pobres, a abnegação para com os iguais e inferiores, a veneração à velhice e o zelo pelo exato cumprimento de todos os deveres religiosos e civis (A BOA NOVA, 23-07-1879, p.1). No entanto, esses princípios cristãos nem sempre eram cumpridos, haja vista existirem grandes contradições na sociedade escravista da época.

Embora D. Antônio de Macedo Costa e todos os demais romanizadores se preocupassem com a educação dos meninos, centraram forças na educação das meninas. A justificativa para isso estava na crença da restauração da sociedade pela educação da mulher. Por isso, o programa educacional católico, de acordo com Ivan Manoel (2008), estava fundamentado numa teoria de educação conservadora, cuja estratégia, ele denominou de "teoria dos círculos concêntricos" que começaria com a educação da menina para se tornar "mãe cristã de filhos cristãos; de filhos cristãos para famílias cristãs; das famílias cristãs para sociedade cristã", chegando-se em breve espaço de tempo à recristianização da sociedade moderna (MANOEL, 2008, p. 58). Por esse motivo, o bispo do Pará, D. Antônio de Macedo Costa, criou o Asilo de Santo Antônio, com a esperança de promover na Amazônia a restauração da sociedade pela verdadeira educação da mulher:

O Asilo de Santo Antônio é uma obra eminentemente diocesana e, portanto digna das simpatias da população paraense. E quando se considera o fim para que foi criado e o grande bem social e regenerador, que é destinado a produzir, não pode deixar de merecer a atenção dos homens sensatos que anelam a restauração social pela verdadeira educação da mulher. (A BOA NOVA, 08-09-1877, p.2)

Para os romanizadores, a educação da mulher era fundamental porque através delas se chegaria à "restauração social", pois a sociedade seria o reflexo das famílias: "se estas são más a sociedade o será também, se boas, a sociedade prosperará”. Nesse sentido, a 
educação oferecida no Asilo de Santo Antônio não teria como missão formar a "mulher mundana", mas a "mulher cristã de trabalho e piedade". Essas duas virtudes seriam na concepção dos padres ultramontanos o maior patrimônio que a mulher poderia ter, pois com elas as mulheres seriam modelo para os filhos e exemplo para os maridos, um anjo a tutelar o lar doméstico (A BOA NOVA, 08-09-1877, p. 2).

Essa crença dos romanizadores na regeneração social pela educação da mulher estava centrada no princípio de que a mulher nasce inclinada para o bem e, se educada na religião católica, o resultado disso seria uma mulher virtuosa, verdadeiro "cenáculo de todas as virtudes" e capaz de realizar as mais heroicas ações. Portanto, educar a mulher cujo coração era notável pela delicadeza e sensibilidade e com nobre tendência para o bem seria uma obra de grande valia para toda sociedade. Nesse sentido, o bispo do Pará, de acordo com os redatores do jornal A Boa Nova, soube dar o valor devido a essa tão importante obra ao empregar esforços para trazer as Irmãs do Instituto de Santa Dorotéia da Europa para dirigir o Asilo e assim iniciar na Amazônia uma nova era: "era de consolação dulcíssimas para o coração do nosso grande bispo, de regeneração social, e consequentemente, de verdadeiro progresso" (A BOA NOVA, 08-09-1877, p.2).

Nesse sentido, a educação da mulher adquiriu um papel central na política romanizadora na Amazônia, pela crença de que ela seria a verdadeira guardiã do lar, aquela que iria influenciar decisivamente a formação dos filhos e ser exemplo para o marido, e com isso, ajudar a promover a regeneração social e consequentemente, ajudar a se chegar ao verdadeiro progresso. As freiras do Instituto de Santa Dorotéia tinham a mesma convicção, por isso foram escolhidas por D. Antonio para serem as dirigentes e educadoras do Asilo de Santo Antônio:

A obra Pia, educando as meninas, pode cultivar a metade da geração que surge. Se esta cresce boa, e sendo tão grande a influência da educação das mães sobre os filhos, também a outra metade deverá necessariamente melhorar. Portanto, as Irmãs deste Instituto tendo sido particularmente escolhidas pela Divina Misericórdia para ser a alma da Pia Obra. (CONSTITUIÇÕES, 1851, p.54)

Para as irmãs Dorotéia, o sucesso do trabalho delas seria garantido pela divina misericórdia e pela forma de trabalho que era "inteiramente evangélico, e por isto, certamente eficaz". Por isso, tinham a certeza de que "educar bem as crianças é reformar o mundo e conduzi-lo a verdadeira vida, como diz Cristo na sua Doutrina" (CONSTITUIÇÕES, 1851, p.54-55).

\section{O Asilo de Santo Antônio e educação feminina sob as orientações da Igreja reformadora}

O Asilo de Santo Antônio foi criado oficialmente em Belém no ano 1878 pelo bispo do Pará, Dom Antônio de Macedo Costa, para atender meninas órfãs, desvalidas e pensionistas. A cidade de Belém foi fundada pelos portugueses no início do século XVII, mais precisamente em 1616, pelo grupo liderado por Francisco Caldeira Castelo Branco, que veio tomar posse do lugar e garantir efetivamente esse território à Coroa portuguesa. De acordo com Arthur Cezar Ferreira Reis, a primeira impressão que Castelo Branco teve sobre o lugar foi: "terra sadia de muitos bons ares, fertilíssima em tudo, inclusive pela abundancia e docilidade do gentio, superior ao restante do Brasil" (REIS, 1993, p.5-7). No 
século XIX, entretanto, de acordo com José da Gama e Abreu (Barão do Marajó), as Províncias no Norte (Pará e Amazonas) eram vistas pelos Estados do Sul com preconceito, ou seja, "somente como serras habitadas por hordas de selvagens bravios, com inóspitos e ínvios sertões com poucos e minguados povoados em que abundam os animais e aves". Segundo José da Gama e Abreu, os próprios livros publicados na Europa sobre a Amazônia continham erros, por isso propunha que os próprios filhos da terra escrevessem sobre ela, mas "sem tocar os extremos de uma ignóbil maledicência, ou de uma benevolência exagerada" (ABREU, 1992, p. 5-6).

O lugar escolhido para a fundação da cidade está localizado na Latitude: $01^{\circ} 23$ '.6 Sul e Longitude: $048^{\circ} 29^{\prime} .5$ Oeste, na região Norte do Brasil, aproximadamente a $160 \mathrm{~km}$ ao sul da linha do Equador (DERGAN, 2006, p.15). A opção pelo lugar, de acordo com Maria de Nazaré Sarges (2010), tinha como objetivo "desembarcar com segurança e ainda fixar seu ponto de resistência a futuros ataques e defesas das terras conquistadas", por isso Castelo Branco construiu sua fortificação em uma ponta de terra alta e cercada de águas. Essa primeira construção era bem rústica feita de madeira e palha "recebeu o nome de Forte do Presépio, atualmente, Forte do Castelo, dando início à formação do primeiro aglomerado urbano, mais tarde conhecido por Feliz Lusitânia e, posteriormente, Santa Maria de Belém do Grão-Pará" (SARGES, 2010, p.61-62).

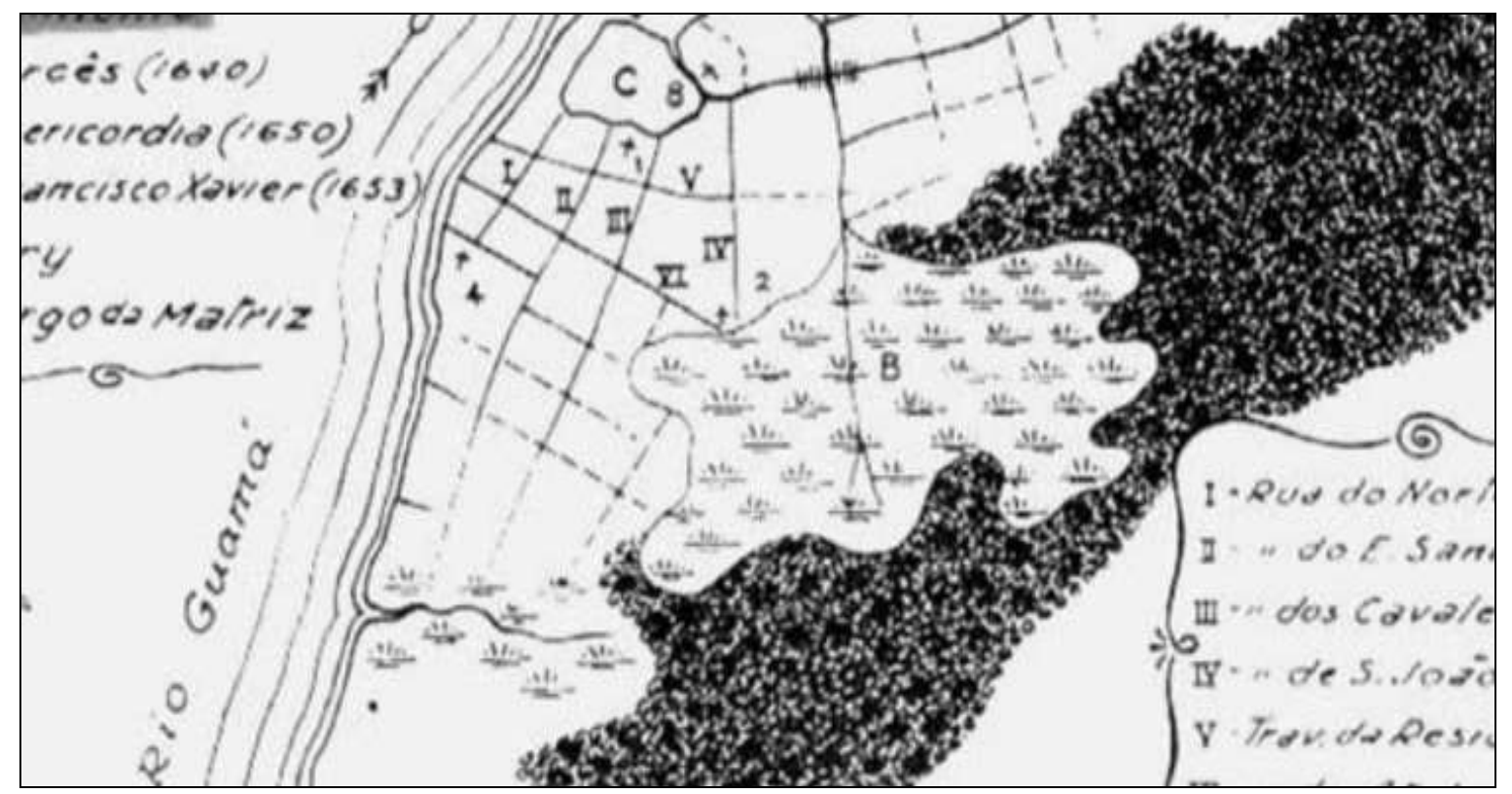

Figura 02: Mapa de Belém do século XVII

Fonte: AMORIM, 2005, p. 139.

O mapa de Belém do século XVII, mais especificamente, dos anos de 1631 a 1661, mostra as primeiras ruas e principais construções, destacando-se a residência dos padres franciscanos ( ${ }^{\circ} 5$ da imagem), lado direito do rio do Piry (letra B), onde foi construído o Convento de Santo Antônio, que, na segunda metade do século XIX, viria a se tornar o Asilo de Santo Antônio.

Na sua origem, em 1871, recebeu o nome de Asilo de Nossa Senhora do Carmo, e funcionava no prédio anexo a igreja do Carmo, antigo Convento Carmelita. Ao mudar-se em 1873 para o prédio do Convento dos padres franciscanos, passou a chamar-se Asilo de Santo Antônio passando a receber também alunas pensionistas cujos pais podiam pagar por seus estudos (LUSTOSA, 1992, p. 130-131). 


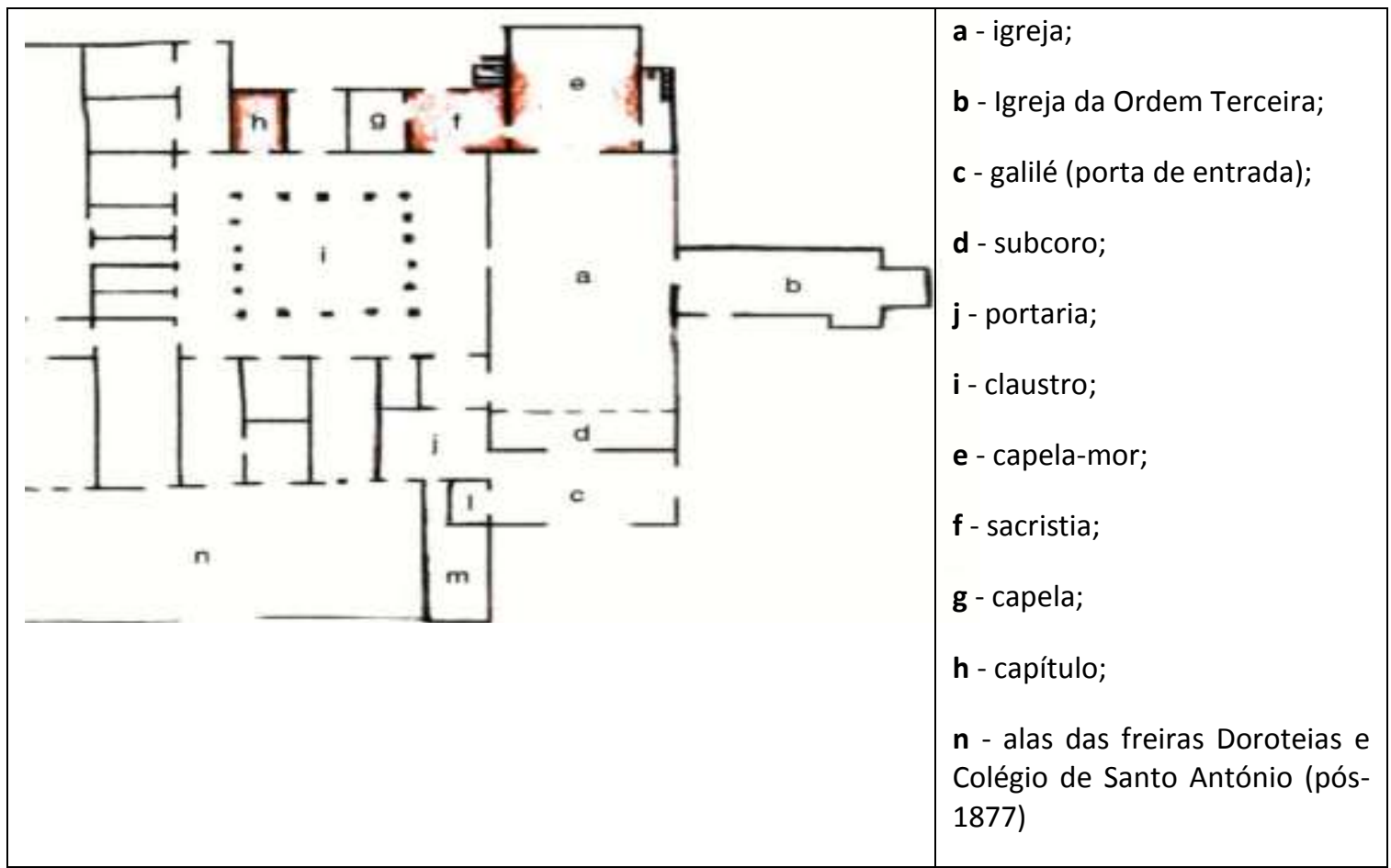

Figura 02: Planta baixa do Convento de Santo António (or. 1627/ reconstrução 1736-1743) de Belém do Pará (reconstituição de Ana Léa Nassar Matos).

Fonte: AMORIM, 2011, p. 104.

$\mathrm{O}$ antigo Convento dos padres franciscanos transformado em Asilo estava situado na antiga freguesia da Campina, hoje bairro da Campina, centro de Belém. $O$ funcionamento do Asilo no prédio desse Antigo Convento só foi possível porque, em 1867, D. Macedo Costa recebeu na forma de caráter perpétuo o prédio da ordem dos franciscanos (BEZERRA NETO, 1998, p. 196).

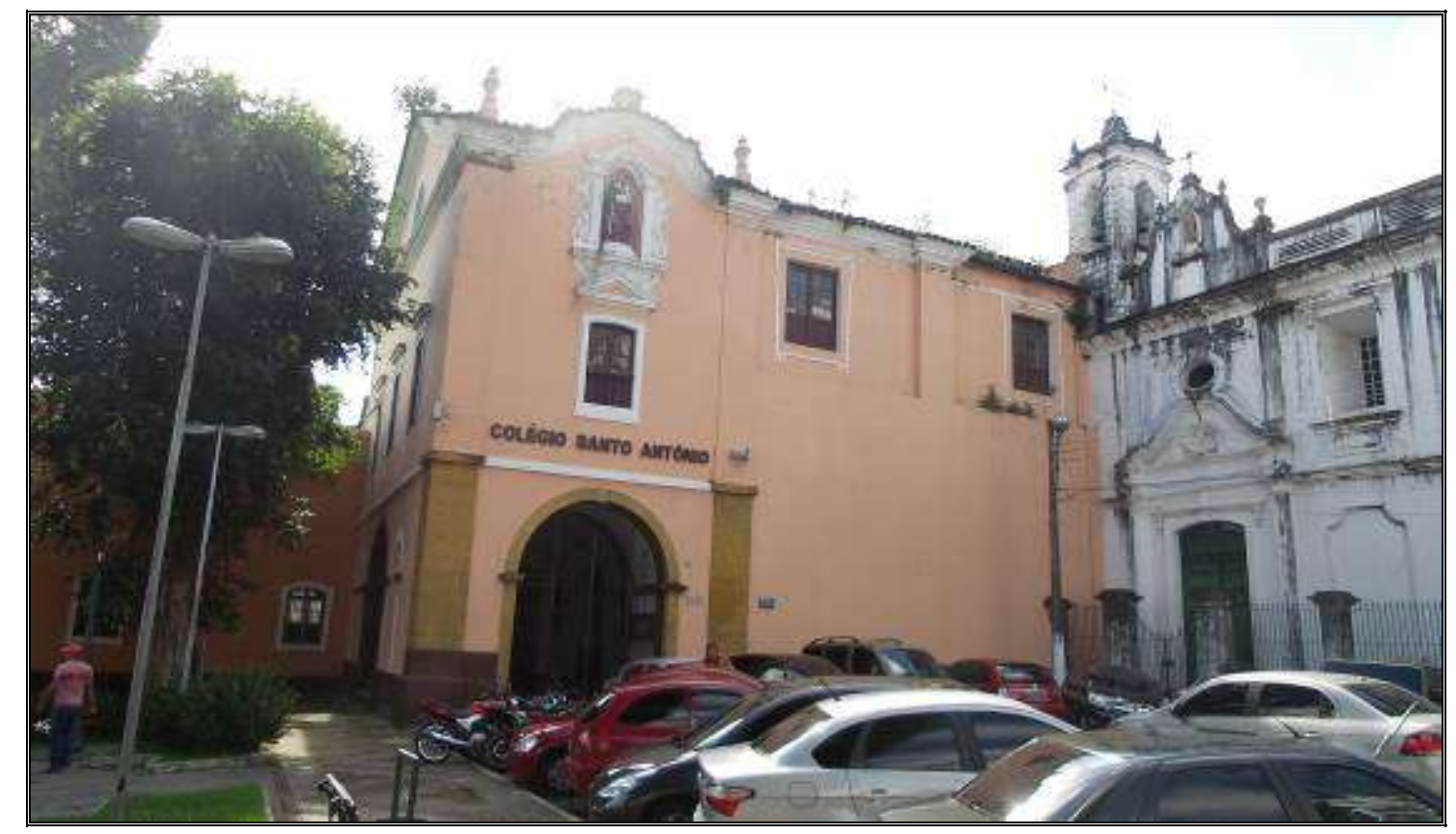

Figura 03: Fachada do Asilo e Colégio de Santo Antônio em Belém do Pará. 2014. Fonte: Benedito Gonçalves Costa, 2014. 
Ao assumirem o Asilo de Santo Antônio em 1878, as irmãs Dorotéias trataram logo de "separar as alunas das órfãs e iniciaram os preparativos para entrada de novas crianças, tanto alunas como órfãs" (MEMÓRIAS, 1998, p. 432). Assim foi criado oficialmente dentro do Asilo, como mostra a imagem abaixo da porta de entrada da instituição, o "Colégio das Educandas" para meninas de origem socialmente mais elevada, que deveriam receber educação diferenciada das pobres.

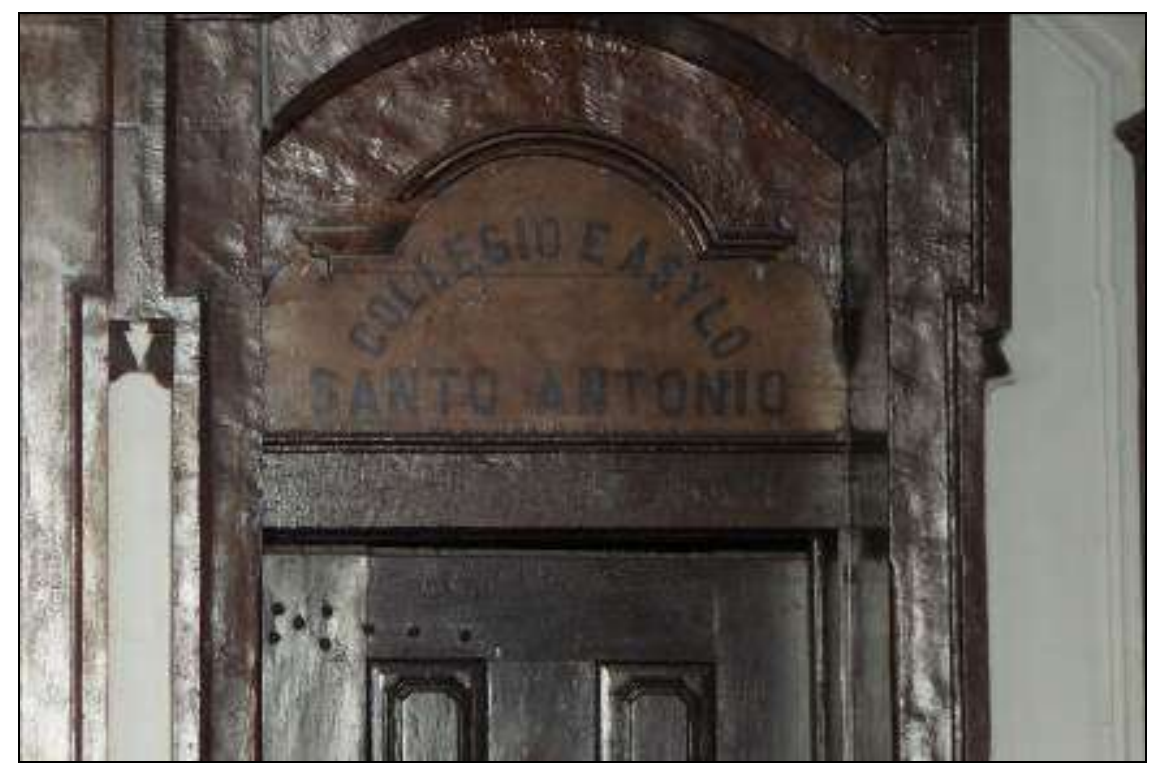

Figura 04: Porta de entrada do Colégio e Asilo de Santo Antônio dentro do pátio de entrada, 2014

Fonte: Benedito Gonçalves Costa, 2014.

As meninas pobres e órfãs deveriam receber educação religiosa, moral e intelectual, já as meninas mais abastadas, denominadas de alunas ou pensionistas, deveriam receber, além disso, uma educação esmerada. Sobre essa separação e educação diferenciada, o Presidente da Província José da Gama Malcher (1878), num trecho do seu Relatório, destaca: "Embora seja o mesmo estabelecimento parece-me racional esta divisão visto como ela é exigida pelas diversas condições da sociedade". Portanto, de acordo com José da Gama Malcher o Asilo das órfãs era "inteiramente distinto do colégio, onde são educadas as pensionistas. As órfãs e desvalidas são mantidas com os exíguos recursos da Diocese e com os donativos de pessoas generosas e caritativas" (PARÁ, 1878, p. 76).

A prática de separar as meninas dentro de uma mesma instituição, defendida pelo Presidente da Província José Malcher como "racional”, era um princípio totalmente aceito pela sociedade escravista brasileira desde o século XVI e reforçada, no final de século XIX, pela crença negativa sobre a mestiçagem cunhada pelo ideário positivistaevolucionista e liberal das teorias raciais como bem mostrou Lilia Schwarcz (1993) na obra "O Espetáculo das Raças".

Quanto ao número de meninas matriculadas no Asilo de Santo Antônio, houve a cada ano, um crescimento significativo. De acordo com o Relatório do Presidente da Província, Pedro Vicente de Azevedo em 1875, o Asilo de Santo Antônio contava com 30 alunas (PARA, 1875, p.14). Quando as Irmãs Doretéias chegaram a Belém em setembro de 1877, encontraram no Asilo 44 meninas, entre elas algumas educandas abastadas, as chamadas pensionistas (MEMÓRIAS, 1998, p. 431). Em 1879, de acordo com Relatório do Presidente da Província, José da Gama Malcher, o número de alunas órfãs e desvalidas 
matriculadas no Asilo passou para 60 meninas, e junto com elas, muitas meninas pensionistas. Esse número foi aumentando a cada ano, chegando, em 1895, um total de 170 meninas matriculadas (AZZI, 2002, p.71).

Esse aumento da matrícula se acelerou principalmente depois de 1878 quando as Irmãs Mestras do Instituto de Santa Dorotéia, vindas da Europa a convite do bispo do Pará D. Macedo Costa, assumiram a direção do Asilo. Além disso, as Irmãs, junto com o bispo D. Macedo Costa, realizaram as seguintes mudanças no Asilo: reforma do prédio, ampliação do número de alunas com a criação do colégio para as meninas pensionistas e modernização da educação a qual seguia as mesmas diretrizes dos colégios administrados pelo Instituto na Europa. Esse Instituto Religioso das Irmãs Mestras de Santa Dortéia foi criado em Roma por Paula Frassinetti e algumas amigas em agosto de 1834 na Paróquia S. Pedro em Quinto al Mare, uma comunidade de Gênova, para educar meninas pobres daquela localidade. Tudo começou quando a jovem Paula Frassinetti (1809-1882) decidiu ajudar seu irmão, o padre José Frassinetti, nos trabalhos paroquiais que ele vinha desenvolvendo naquela comunidade. $\mathrm{O}$ trabalho iniciou com uma escolhinha gratuita "para meninas pobres, a fim de tirá-las da rua e instruí-las segundo sua condição". Nessa escolhinha, Paula Frassinetti e as amigas ensinavam o catecismo, a leitura e trabalhos manuais como coser, fazer malha etc. (ROSSETTO, 1984, p. 33).

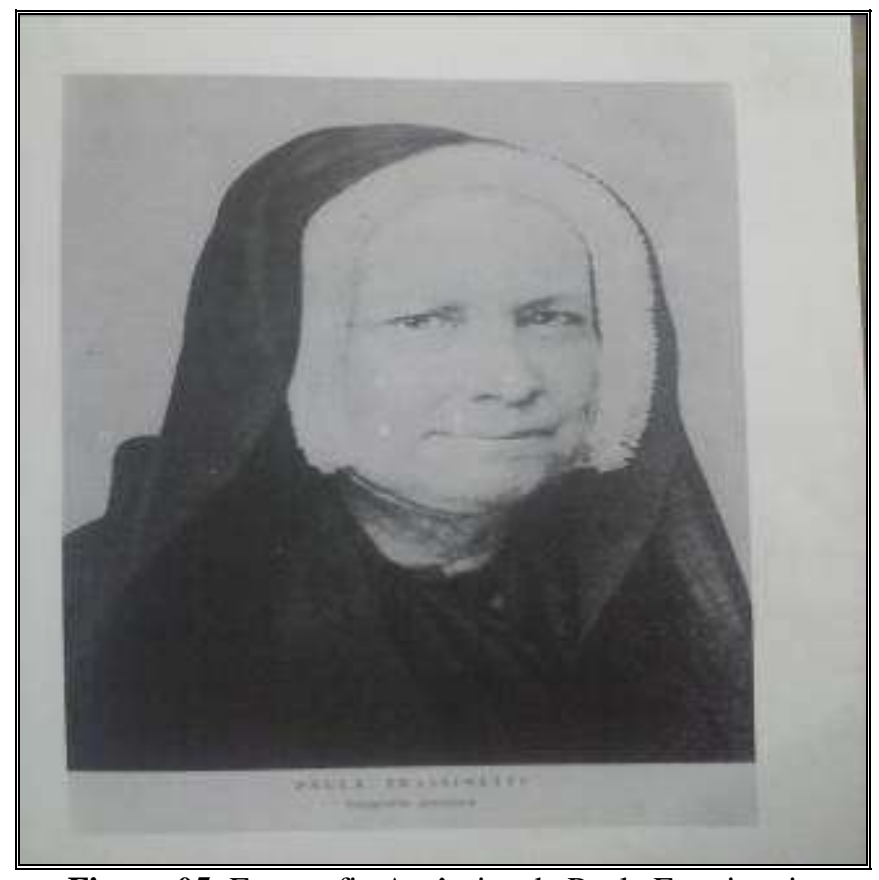

Figura 05: Fotografia Autêntica de Paula Frassinetti Fonte: ROSSETTO, 1984, p. 7.

As educadoras do novo Instituto foram inicialmente chamadas de Filhas da Santa fé até 1835 quando o padre Lucas Passi convidou Paula Frassinetti para assumir o trabalho que ele já vinha desenvolvendo junto às crianças pobres. $\mathrm{O}$ instituto criado pelo referido padre tinha os seguintes nomes: Santa Dorotéia (para meninas) e São Rafael (para meninos). A parir dessa parceria, as Filhas da Santa fé passaram a se chamar Irmãs de Santa Dorotéia, dedicando-se exclusivamente à educação de meninas (ROSSETTO, 1984, p. 52).

Os Asilos e os Colégios administrados pelas Irmãs do Instituto de Santa Dorotéia seguiam as mesmas normas estabelecidas no documento escrito em 1851 por Paula 
Frassinetti, chamado Constituições e Regras do Instituto Religioso das Irmãs Mestras de Santa Dorotéia. Nesse documento, Paula Frassinetti destaca que os dois principais objetivos do Instituto eram: "Cultivar e promover a Obra Pia de Santa Dorotéia e promover a educação cristã das meninas para honrar a Deus e a N. Senhora das Dores" (CONSTITUIÇÕES, 1851, p.54,62).

A educação oferecida nos estabelecimentos educativos das Dorotéias tinha como objetivo preparar as meninas para se tornarem esposas e mães de famílias. De acordo com as Irmãs Dorotéias, uma mulher verdadeiramente cristã poderia fazer um grande bem para a sociedade pela sua qualidade de "mulher mãe de família solidária e cristã, virtuosa e afeiçoada à religião e a seus deveres"(CONSTITUIÇÕES,1851, p.62). Portanto, a mulher cristã seria a guardiã do lar porque com seu exemplo e dedicação poderia ajudar na regeneração do esposo, manter ordem e harmonia do lar, e dar aos filhos a primeira educação:

Quantos esposos que vivem no esquecimento de Deus e da fé podem ser retirados do vício e da desordem, e reconduzidos à virtude, mediante os exemplos, os cuidados, a sabedoria, a doçura e as orações de uma esposa solidamente cristã! Pode-se ainda afirmar que a ordem e a regularidade interna de uma família, a paz e o decoro entre os domésticos, e, sobretudo a primeira educação das crianças, dependem principalmente da mãe; e é por ela que se transmite à geração seguinte o conhecimento, o amor e a prática da religião. (CONSTITUIÇÕES, 1851, p.62)

Diante disso, o ensino nos estabelecimentos educativos dirigidos pelas Irmãs Dorotéias estava centrado em duas bases: educação religiosa e instrução escolar. A primeira seria mais importante, considerada "a base e fim da educação que se deseja dar, e por consequência, o primeiro objeto de ensino". A segunda seria considerada um acessório, mas um acessório necessário para fazer as meninas aprenderem como viver no mundo seguindo adequadamente as conveniências e etiquetas sociais (CONSTITUIÇÕES, 1851, p.63).

Como havia uma educação diferenciada devido à condição social das meninas, nem todos os conteúdos deveriam ser ensinados para todas elas. Para as meninas ricas, educação esmerada (polida, refinada), para as órfãs e desvalidas, educação com ênfase nas prendas domésticas. E mesmo para as meninas de condições sociais mais elevadas, alguns conteúdos, só deveriam ser ensinados se os pais solicitassem e justificassem a necessidade de tal conhecimento para a vida das meninas, como o ensino de língua estrangeira e a arte do ornamento (CONSTITUIÇÕES, 1851, p. 66).

Devido à educação diferenciada para cada grupo de meninas do Asilo de Santo Antônio, é possível que algumas disciplinas escolares como língua estrangeira, piano e canto, e outras, não fossem ofertadas para as órfãs e desvalidas, mas somente para as pensionistas. As primeiras, pela sua posição social, deveriam receber preparação para o mundo do trabalho, ou seja, preparo moral, intelectual e social para uma vida de esposa dedicada, e suporte para o chefe de família, já as pensionistas seriam futuras "damas de salão", ou seja, as esposas de homens bem sucedidos financeiramente, por isso recebiam educação esmerada.

Fazia parte da educação religiosa das meninas a aquisição dos seguintes saberes: aprender o catecismo, maneiras corretas de confessar-se, o respeito e amor à Igreja, o exercício de piedade (orações da manhã e da noite, participar da santa missa, da oferta de ações, meditação e exame de consciência, leitura espiritual, visitas ao Santíssimo, confissão a cada quinze dias e participar da comunhão quando forem julgadas dignas). 
Além disso, recomendava-se às meninas a consolidação da fé pelo temor a Deus e pelo horror ao pecado e desprezo ao mundo com seus prazeres e vaidades, assim como também recomendava-se às meninas a devoção ao Sagrado Coração de Jesus e à Santíssima Virgem Maria (CONSTITUIÇÕES, 1851, p.63-65).

Os demais saberes que as meninas teriam que aprender, para no futuro se tornarem as regeneradoras dos seus lares, faziam parte da instrução escolar. De acordo com as regras do Instituto, as meninas deveriam aprender apenas a Leitura, a Escrita, conhecimentos elementares de Gramática, de História, de Geografia, Aritmética e Trabalhos Manuais. O ensino da aritmética deveria ser necessário apenas "para pequenas contas de compras a varejo que podem exigir um dia a sua condição e seu estado". O ensino de atividades manuais buscava incutir "nas meninas o gosto do trabalho e aos cuidados domésticos, que devem ser a ocupação diária de uma mulher cristã que quer cumprir seus deveres no mudo". Caso os pais das meninas solicitassem, as Irmãs deveriam ofertar também o estudo de língua estrangeira e as artes de ornamento (CONSTITUIÇÕES, 1851, p.63, 66,78).

Nos Relatórios do Presidente da Província do Pará, foi possível observar que as diretoras do Asilo de Antônio procuravam seguir as orientações estabelecidas nas Constituições e Regras do Instituto Religioso das Irmãs Mestras de Santa Dorotéia para o ensino das meninas. O Dr. Manoel Pinto de Souza Dantas Filho, no seu relatório de 1882, afirmava que o Asilo de Santo Antônio, "criado pelo prelado diocesano, é com toda razão considerado pelos pais de família, o melhor colégio onde as meninas podem receber e estão recebendo esmerada instrução nas letras e prendas domésticas" (PARÁ, 1882, p. 6667).

O Dr. Carlos A. de Carvalho, no seu relatório publicado no jornal O Liberal do Pará em 03 de outubro 1885, afirmou que o plano de estudos do Asilo de Santo Antônio consistia "em leitura, gramática portuguesa, história sagrada, catecismo e aritmética". Além disso, as meninas aprendiam "igualmente a costurar, marcar, bordar a banco, matiz, ouro e flores, engomar e cozinhar" (O LIBERAL DO PARA- 03-10-1885, p.1). Portanto, tratava-se de um ensino que oferecia conteúdos básicos do ensino primário, com objetivo de formar a mulher apenas para reger o lar doméstico, ou seja, desejava-se apenas formar a mulher cristã de trabalho e piedade.

\section{Considerações finais}

A partir da segunda metade do século XIX, com o advento da modernidade, o mundo ocidental passou por mudanças significativas com o surgimento de ideias e fenômenos políticos, socais e culturais que passaram a questionar a estrutura da sociedade ocidental-cristã-absolutista. Nesse processo, a influência da Igreja Romana também passou a ser questionada, principalmente na Europa, devido ao processo de laicização dos Estados Nacionais, que deixaram de ser monarquias e transformaram-se em Repúblicas presidencialistas ou parlamentaristas, regidas por uma constituição inspirada nas doutrinas iluministas.

Os princípios que norteavam essa nova forma de conceber a vida em sociedade estavam pautados nos ideais iluministas (liberais e positivas), que, dentre outras coisas, pregavam o fim da relação Estado-Igreja no Brasil, ou seja, o "fim" dos privilégios que a Igreja gozava enquanto religião oficial do Estado.

No campo da educação, os liberais defendiam um ensino laico e sob o total controle do Estado, com uma política de educação moderna, capaz de regenerar a sociedade pelo ensino intelectual e moral do povo. Entretanto, para a Igreja romanizadora, essas ideias não 
passavam de grandes equívocos, pois não haveria possibilidade alguma de se regenerar o Brasil sem a ajuda da Igreja, sem o ensino intelectual, moral e religioso. Esse seria, portanto, o ensino mais importante. Diante disso, a Igreja romanizadora passou a lutar no Brasil pela hegemonia do campo educacional na segunda metade do século XIX, a fim de promover a regeneração da sociedade pela educação, com ênfase na educação da mulher.

A mulher seria, na visão dos romonizadores, a peça principal para a transformação da sociedade brasileira pela sua posição social de regente do lar doméstico. Ali no lar, a mulher cristã de trabalhos e piedade iria influenciar na educação dos filhos e levar o marido ao caminho da fé e dos bons costumes. Assim, cada grupo de meninas do Colégio Santo Antônio recebia educação de acordo com sua origem social, a fim de se manter a estrutura do sistema vigente com cada grupo social cumprindo seu papel. Regenerar a sociedade e promover a civilização seria, para a Igreja, livrá-la das "contaminações" da modernidade. Por isso, o Asilo de Santo Antônio configurou-se como uma das principais políticas do bispo D. Antônio de Macedo Costa para desenvolver a Amazônia, pois sua intenção era que o trabalho das freiras Dorotéias crescesse e se expandisse por toda Província, assim como também as suas demais ações no campo do ensino como os seminários, os colégios para meninos e a catequese das comunidades mais longínquas. Portanto, para D. Antônio de Macedo Costa, a Igreja seria a grande educadora do povo e o Asilo de Santo Antônio, a instituição que iria formar a mulher cristã de trabalho e piedade, aquela que iria ajudar a regenerar a socieade Amazônica.

\section{Referencias}

ABREU, José da Gama e, (o Barão de Marajó). As regiões amazônicas: estudos chorographicos dos Estados do Gram Pará e Amazonas. SECULT, Belém, 1992;

AMORIM, Maria Adelina de Figueiredo Batista. Missão e Cultura dos Franciscanos no Estado do Maranhão e Grão-Pará (Século XVII) : Ao Serviço de Deus, de Sua Majestade e Bem das Almas. Dissertação de Mestrado em História. Lisboa: Universidade de Lisboa, 2005.

ANDERSON, Perry. Linhagens do Estado Absolutista. Brasiliense, $3^{\text {a }}$ Edição. São Paulo, 1995.

AZZI, Riolando. A Presença de D. Antônio de Macedo Costa na Igreja do Brasil. In: $D$. Antônio de Macedo Costa bispo do Pará - Arcebispo Primaz (1830-1891). Cadernos de História da Igreja no Brasil. São Paulo. Edições Loyola - CEPEHIB, 1982.

AZZI, Riolando. Educando pela via do amor: A congregação das Imãs de Santa Dorotéia no Brasil. Vol. II: A expansão da Obra Educativa (1889-1948). Rio de janeiro, 2002.

BEZERRA NETO, José Maia. As luzes da instrução: o Asylo de Santo Antônio de Belém do Pará (1870-1912). In: ACEVEDO MARIN, Rosa Elizabeth. A Escrita da história paraense. (org.). Belém: NAEA-UFPA, 1998.

COSTA, Dom Antônio de Macedo (bispo do Pará). Amazônia: meio de desenvolver sua civilização. Pará, 1883.

CONSTITUIÇÕES e Regras do Instituto Religioso das Irmãs Mestras de Santa Dorotéia. Topografia de G. Batista Marini e B. Morine, 1851.

DELUMEAU, Jean. A Civilização do Renascimento. Editorial Estampa. Lisboa, 1983. 
DERGAN, João Marcelo Barbosa. História, memória e natureza: as comunidades da ilha do Combu-Belém-Pa. Dissertação de Mestrado em História. PPGH-UFPA, 2006.

JORNAL O Liberal do Pará (1869 a 1889). Biblioteca Nacional Digital Brasil: <www.hemerotecadigital.bn.br>. Acesso em: 10 de outubro de 2012.

JORNAL A Estrela do Norte (1863 - 1869) Biblioteca Nacional Digital Brasil: www.hemerotecadigital.bn.br. Acesso em: 10 de outubro de 2012.

JORNAL A Boa Nova (1871 - 1883). Biblioteca Arthur Vianna, no CENTUR-PA.

JULIA, D. A cultura escolar como objeto histórico. Revista Brasileira de História da Educação. Campinas/SP: Autores Associados, nº.1, jan. jun. 2001.

LUSTOSA. D. Antônio de Almeida. D. Macedo costa (bispo do Pará). Belém: SECULT, 1992 (Lendo o Pará 13).

MARTINS, Karla Denise.Civilização Católica: D. Macedo Costa e o Desenvolvimento da Amazônia na segunda metade do século XIX. Revista de História Regional 7(1):73103, Verão, 2002.

MEMÓRIAS acerda da venerável serva de Deus Paula Frassinetti e do Instituto por ela criado. Congregação das Irmãs de Santa Dorotéia. Edicação da Província Portuguesa do Sul, 1998.

MANOEL, Ivan Aparecido. Igreja e Educação (1859 - 1919): uma face do conservadorismo. EDUEM, Maringá, 2008.

MAUÉS, Raymundo Heraldo. Uma outra invenção da Amazônia. Belém: CEJUP, 1999.

NEVES, Fernando Arthur de Fretas. Solidariedade e Conflito: Estado Liberal e Nação Católica no Pará sob o Pastorado de Dom Macedo Costa (1862 - 1889). São Paulo, 2009. 364 f: Tese (doutorado) Pontifícia Universidade Católica (PUC), São Paulo, 2009.

PARÁ. Relatório com que o exmo. Sr. Presidente, Dr. Manuel Pinto de Souza Dantas Filho, passou a administração da Província ao exmo. Sr. 1.o vice-presidente, Dr. José da Gama Malcher. Pará, Typ. do "Liberal do Pará," 1882. Center for Research Libraries Global Resources Network: <http://www.crl.edu/brazil/provincial/par\%C3\%A1>. Acesso em 02 de novembro de 2012.

PARÁ. Relatório com que o exmo. Sr. Presidente da Província, Dr. Pedro Vicente de Azevedo passou a administração da Província ao exmo. Sr. Franciso Maia Corra de Sá e Benevides passou-lhe a administração da Província em 17 de janeiro de 187. Center for Research Libraries Resources Network: <http://www.crl.edu/brazil/provincial/par\%C3\%A1>. Acesso em 02 de novembro de 2012.

RODRIGUES, Denise Simões; FRANÇA, Maria do Perpétuo Socorro G. S. A. A Pesquisa Documental Sócio-Histórica. In: Metodologias e técnicas de pesquisa em educação. Organizadoras: Maria Inês Marcondes, Elizabeth Teixeira, Ivanilde Apoluceno de Oliveira. Belém: EDUEPA, 2010.

ROSSETO, Rosa. Paula Frassinetti: “...em bicos de pé”. Fundadora da Congregação das Imãs de Santa Doroteia. Livraria Braga, 1988.

SANTOS, João. A romanização da Igreja católica na Amazônia (1844-1880). In: HOORNAERT, Eduardo (org.). História da Igreja na Amazônia. Comissão de Estudos da História da Igreja na América Latina - CEHILA. Editora Voz, Petrópolis, 1992. 
SARGES, Maria de Nazaré. Belém: riquezas produzindo a Belle Époque (1870 - 1912). 3 ed. Belém: Paka-Tatu, 2010.

VIEIRA, David Gueiros. O Protestantismo, a Maçonaria e a Questão Religiosa no Brasil. Ed. Brasília: Editora da UNB, 1980.

\footnotetext{
${ }^{1}$ Este artigo é parte constitutiva da pesquisa de mestrado intitulada: "A educação de meninas órfãs, desvalidas e pensionistas no Asilo de Santo Antônio, no pastorado do bispo D. Antônio de Macedo Costa em Belém - Pará (1878 - 1888)", apresentada ao Programa de Pós-Graduação em Educação da Universidade do Estado do Pará, defendida em setembro de 2014.

${ }^{2}$ Professor da educação básica. Graduado em História, Especialista e Mestre em Educação. Integrante do Grupo de Pesquisa História da Educação na Amazônia (GHEDA - UEPA). Doutorando do Programa de PósGraduação em Educação da Universidade Federal do Pará.

${ }^{3}$ Professora Dra . do Programa de Pós-Graduação em Educação da Universidade do Estado do Pará, da Linha de Pesquisa Saberes Culturais e Educação na Amazônia. Integrante do Grupo de Pesquisa História da Educação na Amazônia (GHEDA/ UEPA).

${ }^{4}$ Os jornais A Estrela do Norte (1863 - 1869) e A Boa Nova (1871 - 1883) foram criados pelo bispo do Pará D. Antônio de Macedo Costa, para divulgar suas idéias religiosas romanizadoras na Amazônia.

${ }^{5}$ Documento criado por Paula Frassinetti, fundadora do Instituto das Irmãs Mestras de Santa Dorotéia, em 21 de Setembro de 1851, Roma. Nele estão todas as regras e orientações que as freiras e as meninas deveriam seguir para alcançar o sucesso no trabalho pedagógico e cristão.
}

Recebido: $\quad$ abr/15 $\quad$ Aprovado: $\quad$ jun/15 